\title{
Correction to: Sustainable Green Chemical Processes and their Allied Applications
}

\author{
Inamuddin and Abdullah M. Asiri
}

\section{Correction to:}

Inamuddin, A. M. Asiri (eds.), Sustainable Green Chemical

Processes and their Allied Applications, Nanotechnology in the Life Sciences, https://doi.org/10.1007/978-3-030-42284-4

This book was inadvertently published without the middle initial of the volume editor Abdullah M. Asiri and the second affiliation of Inamuddin. This has now been corrected throughout the book. 